\title{
Learning across levels
}

\author{
Gerry Stahl
}

Published online: 16 February 2013

(C) International Society of the Learning Sciences, Inc. and Springer Science+Business Media New York 2013

The theme of this year's CSCL 2013 conference- "To see the world and a grain of sand: Learning across levels of space, time and scale"- targets a provocative challenge for CSCL, namely that the interactions of collaborative learning be understood, supported and analyzed at multiple levels. As the conference call puts it, "the attention to the theoretical, methodological and technological issues of addressing research at multiple levels is highly relevant to current research in CSCL, as well as to developing an emerging understanding of the epistemological and methodological issues that will shape our intellectual efforts well into the future" (http://isls.org/cscl2013).

The attempt to bridge across levels of analysis - in CSCL theory, analysis and practicestands at the forefront of CSCL research today. CSCL research typically investigates processes at the individual, small-group and community units of analysis. However, individual CSCL studies generally each focus on only one of these units. Moreover, there is little data-based analysis of how the three levels are connected, although it is clear that such connections are crucially important to understanding and orchestrating learning in CSCL settings. The introduction to the last issue of ijCSCL (Stahl 2012b) proposed that the levels of individual learning, group cognition and community knowledge building may be connected by emergent interactional resources, which can mediate between the levels.

\section{Resources across levels in CSCL}

The question of how the local interactional resources that mediate sequential small-group interaction are related to large-scale socio-cultural context as well as to individual learning is an empirical question in each case. There are many ways these connections across levels take place, and it is likely that they often involve mechanisms that are not apparent to participants. In the following, we explore one way of thinking about how such connections can occur: thanks to interactional resources.

In his study of how social institutions can both effect and be effected by small-group interactions, Sawyer (2005, p. 210f) argues that we can conceptualize the interactions between processes at different levels as forms of "collaborative emergence": "During conversational encounters, interactional frames emerge, and these are collective social facts

\footnotetext{
G. Stahl $(\bowtie)$

Drexel University, Philadelphia, PA, USA

e-mail: Gerry@ijCSCL.org
} 
that can be characterized independently of individuals' interpretations of them. Once a frame has emerged, it constrains the possibilities for action." The frames that emerge from smallgroup interactions can take on institutional or cultural-level powers to influence actions at the individual unit. This interplay among levels involves both ephemeral emergents and stable emergents. Sawyer's theory of emergents suggests a relationship among different kinds of resources along the lines pictured in Fig. 1.

While Sawyer's analysis addresses a broad "sociology of social emergence," it can be confined and adapted to the concerns of CSCL. What is most relevant in his theory is the view of emergence arising out of the subtle complexities of language usage and small-group interaction - rather than from the law of large numbers, the interaction of simple rules or the chaotic behavior of non-linear relationships. He thereby rejects the relevance of most popular theories of emergence for CSCL and shifts the focus to the discourse at the smallgroup unit of analysis. The vast variety of interactional emergents form an intermediate level of analysis between the level of individuals and the level of community structures, providing a dynamic and processual understanding of social structures and infrastructures. Analysis focused on these emergent artifacts can deconstruct the reifying processes of emergence that span the group level to both the individual and the social.

The small-group interaction represented in the center of Fig. 1 can be theorized as being based on an "indexical ground of deictic reference" (Hanks 1992). This means that the "common ground" (Clark and Brennan 1991) — which forms a foundation for mutual understanding of what each other says in conversation-consists of a shared system of indexical-reference resources, such as deictic pronouns, which are used to point to unstated topics or resources. The coherence of the interaction and its comprehensibility to the group participants is supported by a network of references, each of which is defined indexically,

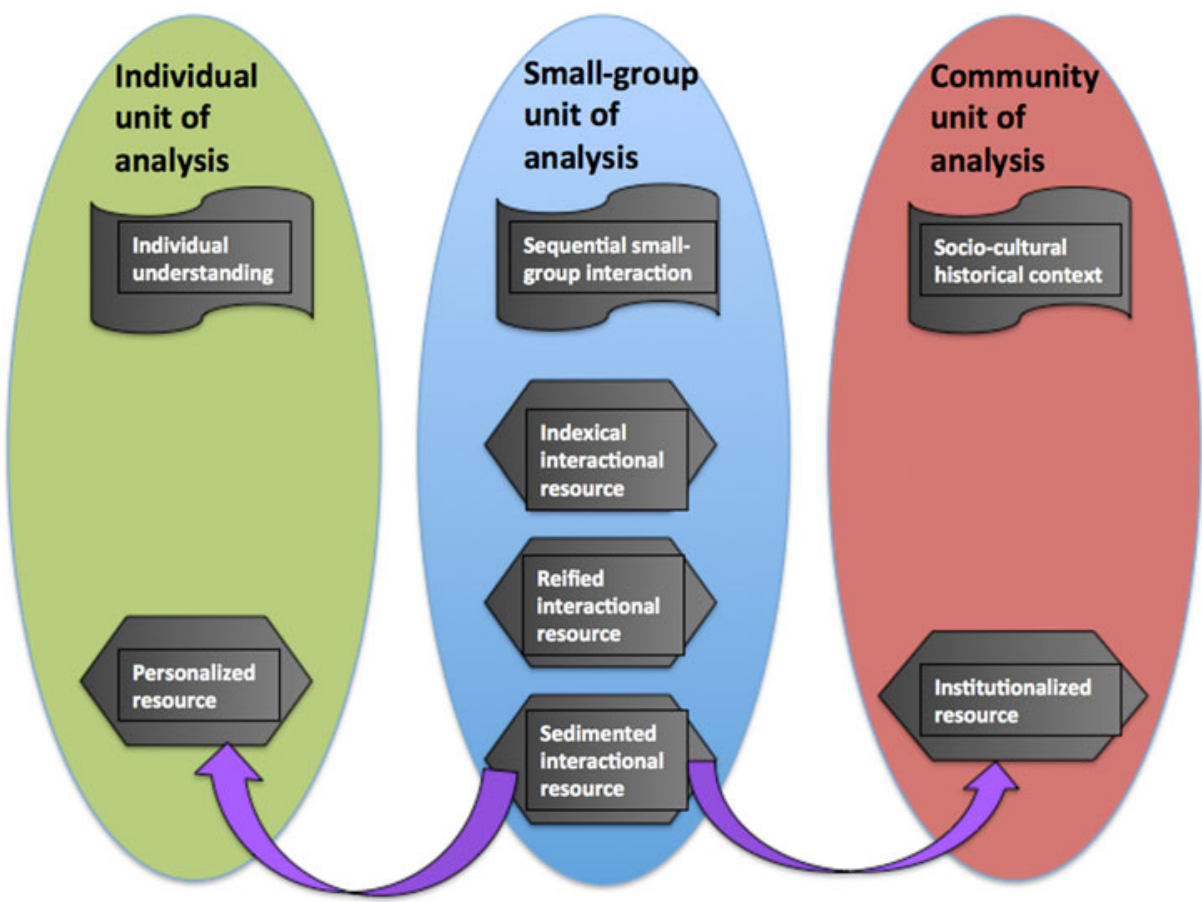

Fig. 1 A diagram of emergent interactional resources bridging levels of analysis 
that is by a pointing within the on-going discourse context ("here," "it," "now," "that point"). Interactional resources, which can be indexically referenced in the interaction, can typically only be understood within their discourse context, but they facilitate meaning making within that context.

Interactional resources can undergo a process like Rabardel's instrumental genesis (Lonchamp 2012; Overdijk et al. 2012; Ritella and Hakkarainen 2012). They may initially be constituted as an object of repeated discussion — an interaction frame (Goffman 1974) — which we might call a reified resource, something capable of being picked out as having at least an "ephemeralemergent" existence. Through repetition within a group discussion, a term or the use of an object might take on a settled significance within the group's current work. Over time, continued usage can result in a sedimented resource, something whose existence has settled into a longer-term "stable-emergent" form, which retains its meaning across multiple group interactions.

A sedimented resource is susceptible to being taken up by a larger community as an institutionalized resource within a structured network of such resources, as in Latour's social-actor networks (Latour 2007), contributing to the socio-cultural-historical context surrounding the interaction. Thus, the institutional resource not only references the social context, but also partially reproduces it in a dialectical relationship of mutual constitution by contributing a new element or revitalizing an old set of resources.

On the other hand, interactional resources at various degrees of reification can also be taken up into the individual understanding of community members as personalized resources, integrated more or less into the intra-personal perspective of one or more group members. The personalization of previously inter-personal resources by individuals renders them into resources that can be referenced in activities of individual understandingcorresponding to processes of micro-genesis in Vygotskian internalization.

The various components of this view of interactional resources have been hinted at in previous theoretical contributions grounded in empirical examples. The progressively emergent character of resources can be seen even in fields of mathematics and science, as documented in the papers in this issue.

The term "reification" goes back to Hegel's dialectical philosophy of mediation (Hegel 1807/1967). Sfard (Sfard 2000; 2008; Sfard and Linchevski 1994) has applied it to the formation of mathematical concepts. Husserl (1936/1989) argued that the ideas of the early geometers became "sedimented" in the cultural heritage of the field of geometry. Livingston (1999) differentiated discovering a mathematical proof from presenting a proof; a transformational process takes place, in which the byways of exploration and possibly even the key insights are suppressed in favor of conforming to the "institutionalized" template of formal deductive reasoning. Netz (1999) (see also the review by Latour 2008) documented the important role of a controlled (restricted and reified) vocabulary to the development, dissemination and learning of geometry in ancient Greece. Analogously, Lemke (1993) argued that learning the vocabulary of a scientific domain such as school physics is inseparable from learning the science. Vygotsky (1930/1978, esp. pp. 56f) noted that the micro-genetic processes of "personalizing" a group practice into part of one's individual understanding-which he conceptually collected under the title "internalization" - are lengthy, complex, non-transparent and little understood. These seminal writings name the processes of reification, sedimentation, institutionalization and personalization of interactional resources; their empirical investigation remains as a major challenge for future CSCL research.

Among the theories influential in CSCL — such as activity theory, distributed cognition and actor-network theory - artifacts play a central role as resources for thought and action. In the foundations of activity theory, Vygotsky (1930/1978) conceives of artifacts as including language as well as tools. In the seminal study of distributed cognition, Hutchins (1996) 
analyzes how the complex of navigational tools, naval procedures for trained teams of people and specialized language work together to accomplish cognitive tasks like ship navigation. He even analyzes data to show how an indexical phrase becomes reified within a dyad's interaction to take on significance that could have led to intra-personal and/or institutional usage. In a witty essay, Latour (1992) shows how a common mechanical door-closer artifact can act to fill the role of an individual person (a doorman), to participate in the politics of a group and to enforce institutional rules. He also argues (Latour 1990) that an inscription artifact like a map on paper - a stable emergent that he refers to as an immutable mobile - can traverse levels from a local discussion in ancient Asia to the social niveau of imperial Europe. However, studies like these have not often been duplicated in the CSCL literature.

Reviews of CSCL research show that few papers in our field have bridged multiple levels of analysis (Arnseth and Ludvigsen 2006; Jeong and Hmelo-Silver 2010). Yet, the desired CSCL research agenda (Krange and Ludvigsen 2008; Stahl et al. 2006; Suthers 2006) calls for a study of representational artifacts and other resources that traverse between individual, small-group and community processes to mediate meaning making. The preceding sketch of a theory of emergent forms of evolving resources could be taken as a refinement of the research agenda for the field of CSCL: a hypothesis about how levels in the analysis of learning are connected; and an agenda for exploration. The contributions in this issue can be read as beginning such an undertaking. They present examples of interactional resources in small-group discussions and indicate how the resources can be seen as bridging levels of analysis.

\section{Resources for collaboration and for mathematics}

The idea of viewing interactional resources as central to mathematical discourse around dynamic geometry is proposed in the article by Diler Öner. Building on an earlier analysis of mathematical learning published in ijCSCL, she argues that rather than focusing on the "coordination of interaction" (Çakir et al. 2009), collaborative activity should be analyzed in terms of the "coordinated use of resources." Participants rely on two major categories of resources when working on a geometry problem within a computer-based dynamicgeometry environment: (1) mathematical and tool-enabled resources (math-content-related) and (2) collaboration resources (relational or social). She proposes a focus on the coordination of these resources - which characterize collaborative dynamic-geometry problem solving - for understanding what goes on in such productive math learning.

The combination of social and content resources brought to bear on geometric problem solving often bridges levels. Social resources - such as greetings, invitations to speak, checks on discourse direction - function to cohere the group out of its individual members, drawing upon community standards and institutional routines. Uses of math resourcessuch as manipulating visual representations, referencing recent findings, expressing relationships symbolically - move fluidly between individual perceptual behavior, group problemsolving sequences and the cultural stockpile of mathematical knowledge. Perhaps the incessant traversal of levels is particularly visible in collaborative math discourse because of its explicit use of multiple layers of reality: a physical drawing, the intended figure, a narrative description, a symbolic expression, the conceptualization, the mathematical object.

Öner's methodological proposal is to track both the math-content-related and the social/ collaborative/relational resources used by students solving dynamic-geometry problems. Math resources may come from graphical, narrative and symbolic representations or expressions of the math problem or from previous math knowledge of culturally transmitted 
concepts, theorems, procedures, symbolisms, etc. Social resources include communication practices, such as the rules of conversational discourse (transactivity, sequentiality, shared attention, argumentation, turn taking, repair, etc.).

Öner's paper cites a number of distinctions drawn in the CSCL literature for contrasting social/collaborative/relational resources with content-related resources:

- An inter-personal-relations space versus a content space (Barron 2000);

- Building a joint problem space (JPS) versus solving a problem (Roschelle and Teasley 1995);

- Temporal dimensions of the JPS versus diachronic content (Sarmiento and Stahl 2008);

- Text chat versus shared-whiteboard graphics (Çakir et al. 2009);

- Project discourse versus mathematical discourse (Evans et al. 2011);

- Spatio-graphical observation (SG) versus technical reflection (T) (Laborde 2004).

The "space" that a group builds up and shares is a structured set of resources gathered by the group (JPS, indexical field, common ground). The resources are "indexical" in the sense that they are only defined within (and thanks to) this constructed space of the specific problem context. Through their discourse, the group compiles these resources as potentially relevant to the problem. In turn, the resources help to define the emergent problem, dialectically, as we will see in the next papers.

Öner generated data to explore the interaction of the contrasting dimensions by having two people work together face-to-face in front of a shared computer on a particular dynamicgeometry problem, whose solution required a mix of spatio-graphical observation and technical reflection involving mathematical theory - a mix of SG and T resources, to use the distinction she adopts from Laborde. She uses this distinction among resources to structure her analysis. In doing so, she shows how these various resources bridge the different units of analysis. Resources of individual perception (during dragging of geometric objects on the computer screen) feed into the group problem solving, just as do references to classical theorems passed down through cultural institutions. They make possible and stimulate the group interaction. This analysis and the others collected in this issue of ijCSCL provide examples of interactional resources at work in CSCL settings.

By analyzing both social and content resources, Öner shows how interrelated these can be. For instance, on line 48 of Excerpt 4, one student says, "now two isosceles, oops, equilateral triangles are formed here." This utterance is deeply indexical. It is pointing to the "here" and "now" of the geometric construction. The student is narrating his work, intersecting two circles to locate the vertices of the desired equilateral triangle (see Fig. 2). The method he is using refers

Fig. 2 Constructing an equilateral triangle

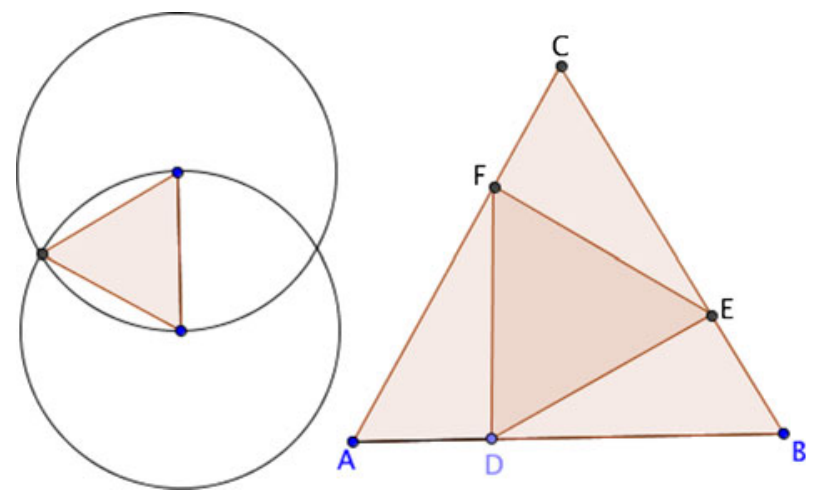


back over 2,500 years to Euclid's first proposition, which teaches this construction. It also notes that one could use either of two potential intersections to construct alternative triangles. This leads his partner to see first one of the intersection points and then the other. Öner notes that the two students collaboratively accomplished this construction; they collectively recalled the procedure in the doing of it, which they had performed in the past but forgotten. She also emphasizes that this utterance includes a self-repair, in which the speaker substitutes a correct term ("equilateral") for an incorrect one - a move she considers social. Repairs are conversational moves aimed at avoiding or correcting potential misunderstandings.

This raises a key theoretical point. Should this utterance be analyzed, categorized or coded as a social resource or as a mathematical one? What is the resource here? Is it the generic conversational resource of self-repair as a "member method" (Garfinkel 1967), or is it the word "equilateral" in the shared language, or is it the geometric concept of equilateral polygon? I.e., is it a conversational move, a linguistic term or a mathematical concept? This is a matter of level of analysis, because one could characterize it in any of these ways. Alternatively, one could argue that the interactional resource that exists here spans multiple levels of analysis, providing an object for analysis at the conversational, linguistic and mathematical levels of the interacting group, the speaking individual and the cultural conceptualization. In other words, such a resource can serve as a boundary object (Star 1989), which can be discussed from different perspectives, focused on different units of analysis.

Öner succeeds in analyzing how her students collaborated on their geometry problem by focusing consistently on the interplay between social and content resources. It may be that we can often follow the movement of discourses across different levels by keeping our eyes on consequential resources. However, other CSCL researchers interpret the theme of resources differently from Öner. This leads them to different insights about their data. It may be that we can use the concept of resource as a boundary object to bring together the disparate theoretical voices. Too often, they seem to talk at cross-purposes, emphasizing differences when they might well be seeing the same phenomenon from different angles.

\section{Scientific representations across levels}

Even if analysts agree in identifying a certain object as a pivotal interactional resource, that does not mean that the nature or meaning of that resource is self-evident to students using it for collaborative learning, as the discussion by Anniken Furberg, Anders Klug and Sten Ludvigsen makes clear. They turn to look at how students make sense of scientific diagrams to support their collaborative learning of physics. The implications of a diagram of a photoelectric cell only emerge gradually for a group of students striving to understand and explain the scientific processes represented there.

The central case study of this paper illustrates how the students gradually produce the meaning of the scientific representation. It is the sense-making process - mediated by the representational resource-that spans levels: The individuals, each with their own approaches and each bringing in different other resources, contribute to the group's collaborative effort, resulting in a group understanding, expressed however awkwardly and partially in their written report. The representation-first from their textbook and then complemented with a second diagram from the Internet - is a contribution from the larger scientific or science-education community.

The paper characterizes the science diagram as a structuring resource. It argues that the representation, as it becomes meaningful to the students, structures the group's sense-making 
work. The structuring takes place on various levels: Interactionally, the group uses the diagram as a deictic resource, pointing to its features either gesturally or linguistically to support the verbal accounts. Individually, the students refer to the diagrams to monitor their own understanding. At the level of science norms, the students attempt to use canonical language to express the sense they are making of the diagram.

Student discourse generally halts in articulation of an idea at the point when everyone seems to understand each other adequately for all practical purposes of the conversation. Even adding a third person to the discourse can extend the discussion somewhat, because the third person brings new questions and needs for understanding. However, when students go to write up a point, they must attain a much higher standard of articulation. They must make their written statement comprehensible and persuasive for a general audience or for people not present to indicate their understanding or agreement. This audience might, for instance, include the teacher, other students in the class or even an audience of unknown potential readers. The audience might require a scientific formulation, using the vocabulary and stylistic genre of physics. Furthermore, since the reading audience is not co-present with the speakers, physical gestures and deictic references to times, places, people and objects present are no longer effective. While the diagram still helps to structure their articulation of the description, the description can no longer rely so heavily on the diagram to help convey their meaning.

It is always true that there is a dialectical circularity or recursive character to the relationship of the discourse context and the utterances that are made within that context; this becomes even clearer in the relationship of the diagram as a structuring and interactional resource to the students' understanding of this resource. The (tentatively understood) diagram helps to structure the students' (increasing) understanding of the diagram itself. The paper nicely shows how the introduction of a second diagram enriches the dialectic by shedding light on the first diagram's meaning through the tension created by the differences between the two representations.

\section{Referential resources for a math problem}

In the third paper, Alan Zemel and Timothy Koschmann take an ethnomethodological (Stahl 2012a) look at the role of resources, representations, referential practices and indexical properties in the mathematical problem-solving interactions of students within a CSCL setting. Viewed in the context of this issue of $i j C S C L$, they develop further some of the central themes of the previous two papers. They concur with the first paper on the importance of tracking the use of resources, and they further emphasize that it is the ongoing specification-in-use that determines the significance of a given resource. They concur with the second, in adopting a concern with representations, and they make even more explicit the extent to which the representational practices - how the representation was built and worked with - contribute to the problem clarification and problem solution.

In theoretical terms, this paper develops the discussion of indexical reference resources by Hanks (1992). It considers two groups of students who were presented with the same problem statement involving combinatorics. The two groups identified completely different sets of "indexical properties," which allowed them to formulate implicitly, share collaboratively and solve mathematically the "same" problem, which, however, had been specified quite differently. In the first team, Bwang8 specified the stair-step pattern of squares in terms of two symmetric sets of lines. Each set of lines followed the pattern: 1, 2, 3, ., n, n. In the second team, Davidcyl specified the problem initially as: "the $\mathrm{n}^{\text {th }}$ pattern has $\mathrm{n}$ more squares than the (n-1)th pattern." 
Ethnomethodologists are keen to observe the work that people do to accomplish what they do. Both teams engaged in intricate coordination of text understanding, sequential drawing, retroactive narrative and symbolic manipulation to make sense of the problem statement they faced and to arrive at a mathematical solution. The work involved in this can be characterized as discovering, proposing and negotiating successive determinations of indexical properties of the problem they were working on. The indexical properties are ways in which the team members can reference aspects of the problem, such as in terms of sets of lines arrayed in specific identifiable patterns. These indexical properties are tied to the local problem-solving context of the respective team. They specify the problem for the team in practical terms, which allow the team to make progress in both understanding and solving the problem.

This approach is appropriate for what Rittel (Rittel and Webber 1984) called "wicked problems." These are non-standard problems, for which the approach to problem solving is not obvious and turns out to be a matter of coming to understand the problem itself. One can imagine Bwang8 entering a completely unknown territory. He was not familiar with the online environment, had never seen the kind of problem statement that was displayed, did not know the other team members and was unclear about what was expected of him. He spotted (visually) an interesting symmetry in the problem and started by stating it as an initial specification about how to view (perceptually and conceptually) the problem. Then he started to draw the problem, so specified, on the shared whiteboard. Davidcyl entered a similarly unknown territory. He started drawing the pattern for $N=4$, as suggested in the text. In so doing, he developed some copy-and-paste practices, which he presented (in the sequentiality of his drawing process as well as in his accompanying description) as tentatively mathematically relevant.

Starting from individual suggestions of indexical properties (by Bwang8 or Davidcyl, respectively), each group developed a growing shared indexical ground of deictic reference. The work of building that space of possible references led the group to make sense of a problem and to discover a path to a solution in mathematical terms. The ground itself is a set of shared interactional resources that allows the team to refer to their object of concern in mutually intelligible ways. By gradually moving from purely deictic terms like "it" or "this," to mathematical terms or abstract symbols, the indexical resources incorporated cultural knowledge and contributed to a less locally situated store of understanding that could be relevant in a larger classroom or culture of school mathematics (including standardized tests). The analysis of how these groups successively and collaboratively re-specify their referential resources suggests approaches to studying how groups make sense of problems and artifacts whose indexical properties are initially unknown or underspecified. This is a foundational concern for CSCL, as "a field of study centrally concerned with meaning and the practices of meaning making in the context of joint activity, and the ways in which these practices are mediated through designed artifacts" (Koschmann 2002).

Coincidentally, in parallel with the publication of this paper, Medina and Suthers (2013) analyzed the same data of Bwang8's virtual math team, showing how the student group re-used over time an emergent set of indexical resources that they developed for co-constructing, coattending to and collaboratively making sense of graphical representations useful for their problem solving. This analysis connected the local unit of analysis to a larger temporal level.

\section{Roles as interactional resources for community meaning making}

If the previous studies take interactional approaches, the paper by Magnus Hontvedt and Hans Christian Arnseth can be considered to be largely at the community-of-practice level. Like the apprenticeship cases of Lave and Wenger (1991), this one is concerned with how 
novices take on the practices of a professional community. Situated in a simulator for training Norwegian sailors, the apprentices role-play at navigating a ship. To bring a ship up the fjord to Oslo, they must bring aboard a local expert. This master pilot helps to establish the professional navigational practices with the apprentices. Interestingly, the pilot insists on using the international language of shipping, English. At times, the trainees slip into Norwegian to reflect on their role-playing, thus marking linguistically the duality of their realities. On the one hand, they are playing the roles of professional sailors interacting in English on the bridge with the local pilot; on the other, they are Norwegian students discussing their educational activities.

Through their role-playing, the participants - whether newcomers or established members of the sailing community - co-create interactionally the context of their learning. Much of the learning consists in this subtle process, which includes integrating interpersonal relations, language constructs, physical artifacts, a designed setting and nautical tasks. Together, this constitutes what the authors call an activity context. Building on the theoretical framework of activity theory, an activity context is closely related to Goffman's concept of frame, discussed above.

The roles taken on by the students are resources for their apprenticeship meaning making. Like roles in a play on stage, they require a willing suspension of disbelief. The analysis in the paper nicely shows how the students fluidly move in and out of their roles and negotiate when to do so, often through code switching between the languages of the two cultures. Never taking the simulation fiction too seriously - as though it were an immutable realitythe analysis reveals how the participants themselves achieve the tenuous existence of the activity context interactionally.

The interactional resources of this learning community are ephemeral emergents — which also means they can collapse. The action can call for a role or an artifact that is missing from the simulation, resulting in improvisation, chaos, laughter. This carries a lesson for all of us: an assemblage of resources for learning cannot foresee all uses. Even the most rehearsed experiment in complex learning is likely to run afoul of glitches. In the best cases, the participants laugh off the troubles ... and the analysts discover insights in the breakdowns.

\section{Annotations as resources for individual learning}

In our final paper of this issue, Evren Eryilmaz, Jakko van der Pol, Terry Ryan, Philip Martin Clark and Justin Mary take a controlled-experiment approach to evaluate the effect of a promising annotation-support tool as a resource for individual learning. By methodologically focusing on the individual student and the individual posting as the units of analysis, this study is able to isolate and quantitatively assess the role of context on these units. While learning is conceptualized as a process that primarily takes place in individual heads, it is enhanced by the interactional level of individuals formulating ideas as posted text and receiving feedback as posted responses from others. Asynchronous discussion forums seem like good media for supporting such enhancement, except that their use causes excessive "cognitive load," reducing the ability to engage in the cognitive processes required for deep learning and therefore counteracting the potential benefits of social interaction.

To make it easier to establish joint reference, the authors of this study provided students with a software indexing function, which graphically connects annotations with relevant selections in the provided educational text. The treatment group uses this software tool as an interactional resource, which is not made available to the control group. The authors study the effect of the resource on learning. They show that the treatment group produces more 
posts coded as "assertions" and "conflicts." The treatment group also does better than the control on the post-test, confirming experimental hypotheses. The conclusion is that the software resource reduced the cognitive load needed to co-construct effective shared interactional resources, like indexical descriptions of target text passages. This allowed the students more cognitive ability to engage in interactive assertions and conflicts. So the focus on the individual unit of analysis allowed this study to evaluate interactions between individual learning, group interaction and socio-technical setting.

The approach and conclusions of this paper can be contrasted with recent findings in CSCL research about "productive failure" (Kapur and Bielaczyck 2012; Kapur and Kinzer 2009; Pathak et al. 2011). Positive findings about productive failure suggest that group processes can underlie individual-level learning in ways that may not show up immediately. The effort to build a joint problem space about a text through interpersonal interaction may confer learning benefits that are not achieved when that task is delegated to software. The interactions among individual learning, group process and institutionally mandated assessments may look quite different depending upon how the research methodology treats the relationships among the levels.

This final paper, taken together with the preceding four, illustrates how different methodologies can be adopted for analyzing resources and their relations to different levels of analysis. What can be taken as a resource for purposes of CSCL research is open to a broad range of approaches and theoretical frameworks. One can find resources for individuals, groups and communities. Often, those resources can be seen as traversing across or mediating between levels. Analysts can fruitfully focus on one aspect or another of this; or they can strive to follow resources across multiple levels.

\section{The CSCL agenda on levels of analysis}

The time has come for CSCL to address the problem of traversing levels of analysis with exacting research. Attempts to research a given level in isolation have run into fundamental limitations. Although it is clear to most researchers that the levels of individual, small-group and community phenomena are inextricably intertwined, opinions differ on how to respond analytically. Religious wars between adherents of different methodological faiths are often based on misunderstandings: people agree on the need to comprehend the levels together, but articulate that need in incommensurate-seeming locutions.

Multiple-method approaches, multi-level statistics and multi-vocal analyses are limited, because they do not explicitly address the complexity of interrelationships among different levels. Some researchers claim that the apparent levels are all reducible to one fundamental level - whether individual cognition, group interaction or the social—while others assume that they can be studied independently. Some say that there is no such thing as different levels, but only different kinds of analysis, although they generally end up talking of individual understandings, group interactions and community practices. There are vague theories that one level is emergent from another or dialectically coupled with it, but these ties are not well worked out or evidenced with CSCL data.

The contributions in this issue provide examples of the kinds of studies and analyses that are needed. In order to comply with one or another standard of rigor, most research focuses on specific relationships within a single unit of analysis. We now also need to generate, compile and analyze data that sheds light on relationships across levels. The idea of tracking interactional resources as they mediate across levels offers one suggestive approach. The different papers discussed here and other referenced theories show that there are many ways 
to conceptualize, analyze and theorize resources. One can conceive of the resources as interactional resources, indexical-reference resources, ephemeral emergents, immutable mobiles, social and content resources, structuring resources, representational resources, framing resources, role-playing resources, cognitive resources, level-traversing or boundary-spanning resources. This journal issue is not meant to define or defend a particular tack, but to suggest interactional resources as a candidate boundary object for discussion across competing approaches. The editorial introduction has not tried to propose a consistent position, but rather to raise some questions about what can be meant by resources for computer-supported collaborative learning, in the hope of stimulating thinking for the CSCL 2013 conference.

Acknowledgements This problematic emerged from interactions with my co-organizers of the workshops on levels at ICLS 2012 and CSCL 2013: Heisawn Jeong, Keith Sawyer, Dan Suthers, Sten Ludvigsen. It was furthered through discussions with Diler Öner, Alan Zemel and Tim Koschmann. Of course, none of these people or the other members of the $i j C S C L$ Board agree entirely with the views expressed above.

\section{References}

Arnseth, H. C., \& Ludvigsen, S. (2006). Approaching institutional contexts: Systemic versus dialogic research in CSCL. International Journal of Computer-Supported Collaborative Learning, 1(2), 167-185.

Barron, B. (2000). Achieving coordination in collaborative problem-solving groups. The Journal of the Learning Sciences, 9(4), 403-436.

Çakir, M. P., Zemel, A., \& Stahl, G. (2009). The joint organization of interaction within a multimodal CSCL medium. International Journal of Computer-Supported Collaborative Learning. 4(2), 115-149. Web: http://GerryStahl.net/pub/ijCSCL_4_2_1.pdf.

Clark, H., \& Brennan, S. (1991). Grounding in communication. In L. Resnick, J. Levine, \& S. Teasley (Eds.), Perspectives on socially-shared cognition (pp. 127-149). Washington, DC: APA.

Evans, M. A., Feenstra, E., Ryon, E., \& McNeill, D. (2011). A multimodal approach to coding discourse: Collaboration, distributed cognition, and geometric reasoning. International Journal of ComputerSupported Collaborative Learning, 6(2), 253-278.

Garfinkel, H. (1967). Studies in ethnomethodology. Englewood Cliffs: Prentice-Hall.

Goffman, E. (1974). Frame analysis: An essay on the organization of experience. New York: Harper \& Row.

Hanks, W. (1992). The indexical ground of deictic reference. In A. Duranti \& C. Goodwin (Eds.), Rethinking context: Language as an interactive phenomenon (pp. 43-76). Cambridge: Cambridge University Press.

Hegel, G. W. F. (1807/1967). Phenomenology of spirit (J. B. Baillie, Trans.). New York, NY: Harper \& Row.

Husserl, E. (1936/1989). The origin of geometry (D. Carr, Trans.). In J. Derrida (Ed.), Edmund Husserl's origin of geometry: An introduction. (pp. 157-180). Lincoln, NE: University of Nebraska Press.

Hutchins, E. (1996). Cognition in the wild. Cambridge: MIT Press.

Jeong, H., \& Hmelo-Silver, C. (2010). An overview of CSCL methodologies. Paper presented at the 9th International Conference of the Learning Sciences. Chicago, IL. Proceedings pp. 921-928.

Kapur, M., \& Bielaczyck, K. (2012). Designing for productive failure. The Journal of the Learning Sciences, 21(1), 45-83.

Kapur, M., \& Kinzer, C. (2009). Productive failure in CSCL groups. International Journal of ComputerSupported Collaborative Learning, 4(1), 21-46.

Koschmann, T. (2002). Dewey's contribution to the foundations of CSCL research. In G. Stahl (Ed.), Computer support for collaborative learning: Foundations for a CSCL community: Proceedings of CSCL 2002 (pp. 17-22). Boulder: Lawrence Erlbaum Associates.

Krange, I., \& Ludvigsen, S. (2008). What does it mean? Students' procedural and conceptual problem solving in a CSCL environment designed within the field of science education. International Journal of Computer-Supported Collaborative Learning, 3(1), 25-51.

Laborde, C. (2004). The hidden role of diagrams in pupils' construction of meaning in geometry. In C. H. J. Kilpatrick \& O. Skovsmose (Eds.), Meaning in mathematics education (pp. 1-21). Dordrecht, Netherlands: Kluwer Academic Publishers. 
Latour, B. (1990). Drawing things together. In M. Lynch \& S. Woolgar (Eds.), Representation in scientific practice. Cambridge: MIT Press.

Latour, B. (1992). Where are the missing masses? The sociology of a few mundane artifacts. In W. E. Bijker \& J. Law (Eds.), Shaping technology/building society (pp. 225-227). Cambridge: MIT Press.

Latour, B. (2007). Reassembling the social: An introduction to actor-network-theory. Cambridge: Cambridge University Press.

Latour, B. (2008). The Netz-works of Greek deductions. Social Studies of Science, 38(3), 441-459.

Lave, J., \& Wenger, E. (1991). Situated learning: Legitimate peripheral participation. Cambridge: Cambridge University Press.

Lemke, J. L. (1993). Talking science: Language, learning and values. Norwood: Ablex.

Livingston, E. (1999). Cultures of proving. Social Studies of Science, 29(6), 867-888.

Lonchamp, J. (2012). An instrumental perspective on CSCL systems. International Journal of ComputerSupported Collaborative Learning, 7(2), 211-237.

Medina, R., \& Suthers, D. D. (2013). Inscriptions becoming representations in representational practices. The Journal of the Learning Sciences. 22(1), 33-69.

Netz, R. (1999). The shaping of deduction in Greek mathematics: A study in cognitive history. Cambridge: Cambridge University Press.

Overdijk, M., Diggelen, W., Kirschner, P., \& Baker, M. (2012). Connecting agents and artifacts in CSCL: Towards a rationale of mutual shaping. International Journal of Computer-Supported Collaborative Learning, 7(2), 193-210.

Pathak, S. A., Kim, B., Jacobson, M. J., \& Zhang, B. H. (2011). Learning the physics of electricity: A qualitative analysis of collaborative processes involved in productive failure. International Journal of Computer-Supported Collaborative Learning, 6(1), 57-73.

Ritella, G., \& Hakkarainen, K. (2012). Instrumental genesis in technology-mediated learning: From double stimulation to expansive knowledge practices. International Journal of Computer-Supported Collaborative Learning, 7(2), 238-258.

Rittel, H., \& Webber, M. M. (1984). Planning problems are wicked problems. In N. Cross (Ed.), Developments in design methodology (pp. 135-144). New York: John Wiley \& Sons.

Roschelle, J., \& Teasley, S. (1995). The construction of shared knowledge in collaborative problem solving. In C. O’Malley (Ed.), Computer-supported collaborative learning (pp. 69-197). Berlin: Springer Verlag.

Sarmiento, J., \& Stahl, G. (2008). Extending the joint problem space: Time and sequence as essential features of knowledge building. Paper presented at the International Conference of the Learning Sciences (ICLS 2008). Utrecht, Netherlands. Web: http://GerryStahl.net/pub/icls2008johann.pdf.

Sawyer, R. K. (2005). Social emergence: Societies as complex systems. Cambridge: Cambridge University Press.

Sfard, A. (2000). Symbolizing mathematical reality into being - or how mathematical discourse and mathematical objects create each other. In P. Cobb, E. Yackel, \& K. McClain (Eds.), Symbolizing and communicating in mathematics classrooms: Perspectives on discourse, tools, and instructional design (pp. 37-98). Mahwah: Lawrence Erlbaum Associates.

Sfard, A. (2008). Thinking as communicating: Human development, the growth of discourses and mathematizing. Cambridge: Cambridge University Press.

Sfard, A., \& Linchevski, L. (1994). The gains and the pitfalls of reification - the case of algebra. In P. Cobb (Ed.), Learning mathematics: Constructivist and interactionist theories of mathematical development (pp. 87-124). Dodrecht: Kluwer.

Stahl, G. (2012a). Ethnomethodologically informed. International Journal of Computer-Supported Collaborative Learning, $7(1), 1-10$.

Stahl, G. (2012b). Traversing planes of learning. International Journal of Computer-Supported Collaborative Learning, 7(4), 467-473.

Stahl, G., Koschmann, T., \& Suthers, D. (2006). Computer-supported collaborative learning: An historical perspective. In R. K. Sawyer (Ed.), Cambridge handbook of the learning sciences (pp. 409-426). Cambridge: Cambridge University Press.

Star, S. L. (1989). The structure of ill-structured solutions: Boundary objects and heterogeneous distributed problem solving. In L. Gasser \& M. N. Huhns (Eds.), Distributed artificial intelligence (pp. 37-54). San Mateo: Morgan Kaufmann.

Suthers, D. D. (2006). Technology affordances for intersubjective meaning making: A research agenda for CSCL. International Journal of Computer-Supported Collaborative Learning, 1(3), 315-337.

Vygotsky, L. (1930/1978). Mind in society. Cambridge, MA: Harvard University Press. 